\title{
Chicken bile powder protects against $\alpha$-naphthylisothiocyanate- induced cholestatic liver injury in mice
}

\author{
Yi-Fei $\mathrm{Li}^{1,}{ }^{*}$, Jia-Sheng $\mathrm{Wu}^{1,}{ }^{*}$, Yuan-Yuan $\mathrm{Li}^{1}$, Yan Dai ${ }^{1}$, Min Zheng ${ }^{1}$, Jia-Kai Zeng ${ }^{1}$, \\ Guo-Feng Wang ${ }^{1}$, Tian-Ming Wang ${ }^{1}$, Wen-Kai Li $^{1}$, Xue-Yan Zhang ${ }^{1}$, Ming Gu$^{2}$, \\ Cheng Huang ${ }^{2}$, Li Yang ${ }^{3}$, Zheng-Tao Wang ${ }^{4}$ and Yue-Ming Ma1,5 \\ ${ }^{1}$ Department of Pharmacology, School of Pharmacy, Shanghai University of Traditional Chinese Medicine, Shanghai 201203, \\ China \\ ${ }^{2}$ School of Pharmacy, Shanghai University of Traditional Chinese Medicine, Shanghai 201203, China \\ ${ }^{3}$ Research Centre for Traditional Chinese Medicine of Complexity Systems, Shanghai University of Traditional Chinese \\ Medicine, Shanghai, China \\ ${ }^{4}$ Shanghai Key Laboratory of Complex Prescription and MOE Key Laboratory for Standardization of Chinese Medicines, \\ Institute of Chinese Materia Medica, Shanghai University of Traditional Chinese Medicine, Shanghai 201203, China \\ ${ }^{5}$ Shanghai Key Laboratory of Compound Chinese Medicines, Shanghai University of Traditional Chinese Medicine, Shanghai \\ 201203, China \\ *These authors have contributed equally to this work \\ Correspondence to: Yue-Ming Ma, email: mayueming_117@hotmail.com \\ Zheng-Tao Wang, email: ztwang@shutcm.edu.cn
}

Keywords: intrahepatic cholestasis; chicken bile powder; FXR; bile acid; metabolomics

Received: January 27, $2017 \quad$ Accepted: July 26, $2017 \quad$ Published: September 27, 2017

Copyright: Li et al. This is an open-access article distributed under the terms of the Creative Commons Attribution License 3.0 (CC BY 3.0), which permits unrestricted use, distribution, and reproduction in any medium, provided the original author and source are credited.

\section{ABSTRACT}

This study explored the effects of chicken bile powder (CBP), a 2000-yearold Chinese medicine, on a-naphthyl isothiocyanate (ANIT)-induced intrahepatic cholestasis in mice. CBP treatment for 14 days significantly ameliorated ANITinduced changes in serum alanine aminotransferase, aspartate aminotransferase, bile acids, bilirubin, y-glutamyl transpeptidase, alkaline phosphatase, and liver tissue morphology. Serum metabolomics showed changes in 24 metabolites in ANITexposed mice; 16 of these metabolites were reversed by CBP treatment via two main pathways (bile acid biosynthesis and arachidonic acid metabolism). Additionally, CBP administration markedly increased fecal and biliary bile acid excretion, and reduced total and hydrophobic bile acid levels in the livers of cholestatic mice. Moreover, CBP increased liver expression of bile acid efflux transporters and metabolic enzymes. It also attenuated ANIT-induced increases in hepatic nuclear factor-kB-mediated inflammatory signaling, and increased liver expression of the nuclear farnesoid $X$ receptor (FXR) in cholestatic mice. CBP also activated FXR in vitro in HEK293T cells expressing mouse $\mathrm{Na}^{+}$-taurocholate cotransporting polypeptide. It did not ameliorate the ANIT-induced liver injuries in FXR-knockout mice. These results suggested that CBP provided protection from cholestatic liver injury by restoring bile acid homeostasis and reducing inflammation in a FXR-dependent manner.

\section{INTRODUCTION}

Intrahepatic cholestasis is a clinical syndrome associated with the systemic and intrahepatic accumulation of toxic bile acids (BAs), which ultimately cause hepatobiliary injury [1]. Several liver diseases can develop due to intrahepatic cholestasis, including biliary atresia, primary sclerosing cholangitis, and primary 
biliary cirrhosis [2]. The natural BA ursodeoxycholic acid (UDCA) is the first and currently most established medical treatment for intrahepatic cholestasis, and this has been used to treat the early stages of primary biliary cirrhosis [3]. However, some patients do not respond to UDCA [4]. Therefore, the development of novel therapeutic approaches to cholestatic liver disorders is required.

The enterohepatic circulation of BAs is mediated by a number of metabolic enzymes and transporters $[5$, 6]. Drug intervention [7-10], pregnancy [11], and gene mutation $[12,13]$ can alter the expression or function of efflux transporters and metabolic enzymes. This can result in the hepatic retention of toxic BAs, which can damage the liver by inducing mitochondrial dysfunction and hepatocyte apoptosis or necrosis [14, 15]. Recent studies have shown that nuclear receptors can regulate these BA transporters and metabolic enzymes, and thus play an important role in maintaining BA homeostasis $[16,17]$. The farnesoid X receptor (FXR) is one of the important nuclear receptors in this context. Activation of FXR provides multiple benefits that can reduce cholestatic liver injury, including the induction of efflux transporters and modulation of metabolic enzyme expression $[18,19]$. FXR activation can also decrease hepatic inflammation mediated by the nuclear factor (NF)- $\kappa B$ signaling pathway [20, 21]. Therefore, activation of FXR represents a therapeutic target for intrahepatic cholestasis.

Traditional medicines and natural products have been widely used to treat cholestasis for thousands of years [22-24]. Dried black bear's bile was recommended in China for the treatment of jaundice during the Tang dynasty (618-907 A.D.), as documented in the Tang Materia Medica, the first state pharmacopoeia [25]. However, the application of bear's bile is greatly restricted by its availability and by ethical considerations. Chicken bile (CB), another ancient traditional Chinese medicine, was first recorded in the classic book "Ming Yi Bie Lu", and has been used to treat respiratory and ophthalmological conditions since the Han Dynasty [26]. However, it is not known whether $\mathrm{CB}$ has protective effects against cholestatic liver injury. $\mathrm{CB}$ consists of some BAs, notably taurochenodeoxycholic acid (TCDCA; around $80 \%$ ) and taurocholic acid (TCA; around 17\%) [27]. TCDCA can be converted into chenodeoxycholic acid (CDCA) by intestinal bacteria [28]. It has been confirmed that CDCA is the main FXR ligand [16]. Therefore, we wished to investigate whether $\mathrm{CB}$ powder (CBP) protected against the liver damage induced by cholestasis, and whether this involved FXR activation. The purpose of this study was to address these questions in mice with $\alpha$-naphthyl isothiocyanate (ANIT)-induced cholestasis. Our results might provide novel insights into the potential of novel naturally occurring compounds to treat intrahepatic cholestasis.

\section{RESULTS}

\section{CBP ameliorates ANIT-induced cholestatic liver injury}

As shown in Figure 1A, serum alanine aminotransferase (ALT) and aspartate aminotransferase (AST), which provide biochemical indicators of hepatic cell damage, were increased in ANIT-induced mice. CBP treatment dose-dependently reduced these increases (Figure 1A and Supplementary Figure 1). Likewise, CBP administration reversed ANIT-induced increases in serum alkaline phosphatase (ALP), $\gamma$-glutamyl transpeptidase $(\gamma-\mathrm{GT})$, total bilirubin (TBIL), direct bilirubin (DBIL), and total BAs (TBA); these are all biomarkers of cholestasis (Figure 1A and Supplementary Figure 1). In addition, light microscopy showed that the liver tissue of the vehicle-treated group exhibited a normal structure (Figure 1B). However, liver tissue specimens from the ANIT group showed acute inflammatory cell infiltration, edema, and hepatic necrosis (Figure 1B). ANIT mice treated with CBP exhibited a mild degree of hepatocyte hydropic degeneration, with less inflammatory cell infiltration (Figure 1B). Abnormal dilatation of the endoplasmic reticulum was found in the ANIT-treated group using electron microscopic analysis, and this was significantly ameliorated by CBP (Figure 1C). As shown in Supplementary Figure 2, CBP treatment had no effect on liver function or the endoplasmic reticulum in normal mice. Taken together, these results suggested that CBP alleviated the cholestatic liver injury induced by ANIT.

\section{Serum metabolomics study of CBP in cholestatic mice}

The quality control (QC) samples clustered tightly in positive and negative modes in the principal components analysis (PCA) plot (Figure 2Aa and 2Ab), illustrating the stability of the liquid chromatography/mass spectrometry method throughout the whole run (methodology validation is shown in Supplementary Table 1). Orthogonal partial least squares discriminant analysis (OPLS-DA) was employed to compare the vehicle- and ANIT-treated groups (Supplementary Figure 3A-3B), and the ANITand ANIT+CBP-treated groups (Supplementary Figure 3C-3D); this facilitated the identification of potential differential metabolites. After screening with "VIP $>1.00$ " and "p $<0.05$ ", $211(\mathrm{ESI}+)$ and 293 (ESI-) differential metabolites were identified between the vehicle- and ANITtreated groups, while 239 (ESI+) and 347 (ESI-) differential metabolites were identified between the ANIT- and ANIT+CBP-treated groups. Figure $2 \mathrm{Ac}$ and $2 \mathrm{Ad}$ shows the OPLS-DA results, indicating an appreciable separation of the data relating to these three groups. The model statistics, $\mathrm{R}^{2} \mathrm{X}, \mathrm{R}^{2} \mathrm{Y}$, and $\mathrm{Q}^{2}$, indicated that the models were stable and reliable, with high predictive ability. 


\section{Identification of differential metabolites}

The differential metabolites indicated by the comparison between each pair of groups are presented in Supplementary Tables 2 and 3. As compared with the normal control group, 24 serum metabolites showed significantly different levels in the ANIT group and 16 of these differences were reversed by CBP intervention (Table 1). Seven of the 16 differential metabolites were identified by authenticated standards, and the others were deduced on the basis of accurate molecular weights, tandem mass spectrometry fragments, and metabolomics databases. The metabolites that showed significant changes included amino acids, BAs, fatty acids, phospholipids, and inflammatory mediators. Figure $2 \mathrm{~B}$ provides a heat map showing how the levels of these metabolites varied among these three study groups.

\section{Analysis of the metabolic pathways affected by CBP}

In order to explore the possible metabolic pathways that were affected by CBP in mice with cholestasis, the

A
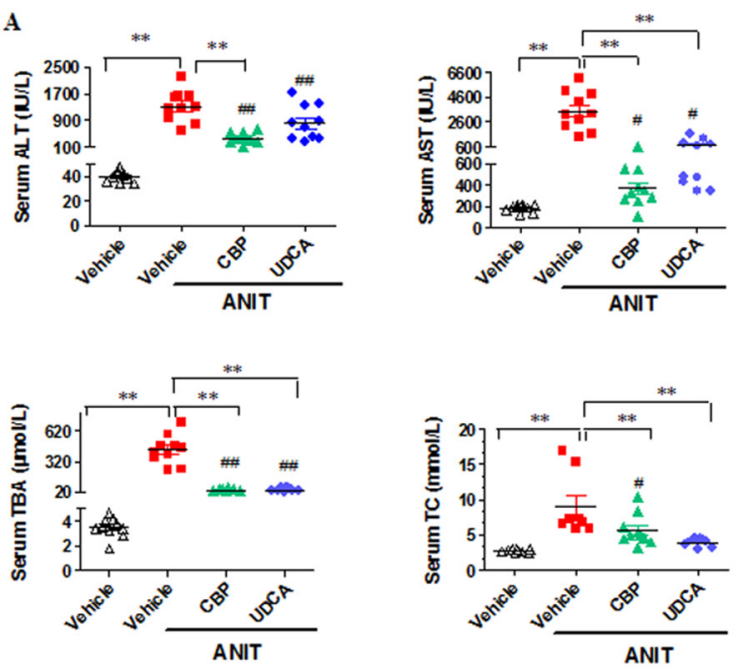

B
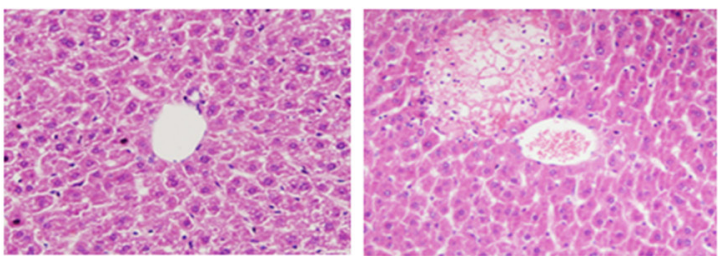

C

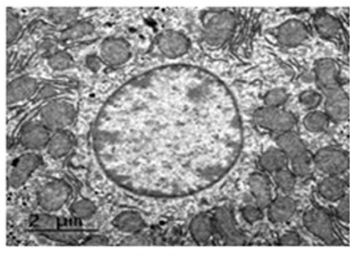

Vehicle

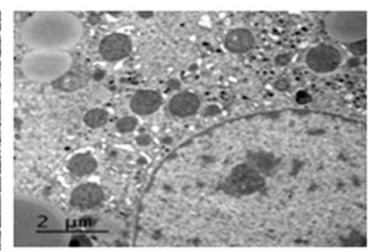

Vehicle+ ANIT
16 endogenous metabolites that were affected by ANIT and reversed by CBP were imported into Metaboanalyst. The main metabolic pathways that these molecules were associated with included primary BA biosynthesis, arachidonic acid metabolism, sphingolipid metabolism, cysteine and methionine metabolism, taurine and hypotaurine metabolism, and steroid hormone biosynthesis (Supplementary Table 4). The top two pathways influenced by CBP were primary BA biosynthesis and arachidonic acid metabolism (Supplementary Table 4).

\section{CBP reverses disordered $\mathrm{BA}$ homeostasis in cholestatic mice}

As compared with the vehicle group, the total serum and liver BA levels were significantly increased in the ANIT-treated group. However, CBP treatment reduced the TBA level in serum (Figure 1A) and liver (Figure 3). Moreover, 18 individual BA levels in mouse serum, liver, and bile were shown in Figure 4. In cholestatic
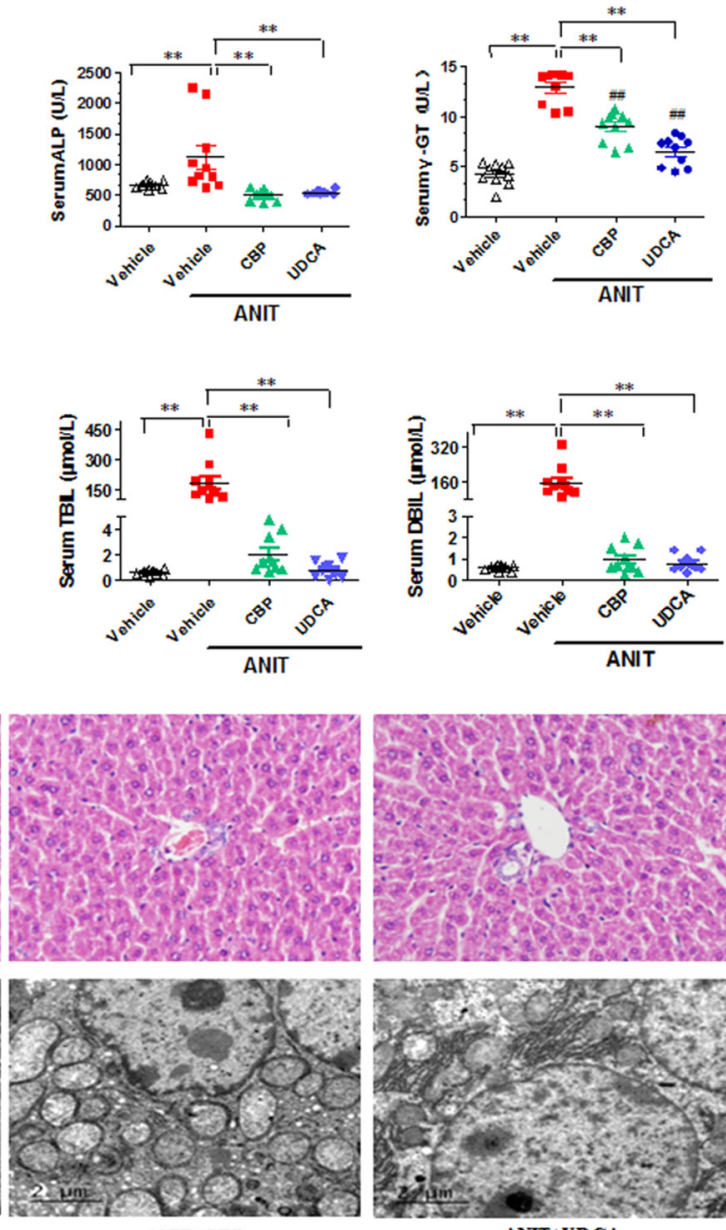

ANIT +CBP
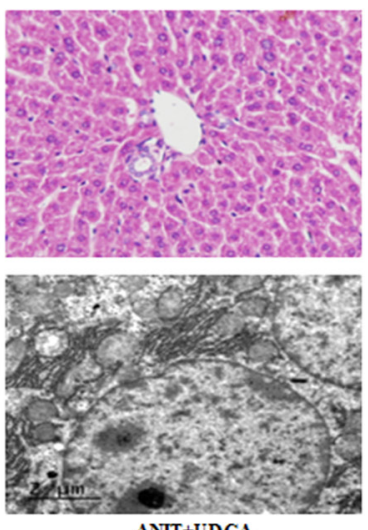

ANIT+UDCA

Figure 1: CBP ameliorates ANIT-induced intrahepatic cholestasis in mice. (A) Serum biochemical parameters. (B) Liver morphology was observed by light microscopy (original magnification $\times 200$ ), and $(\mathbf{C})$ microstructure was observed by electron microscopy (scale bar $2 \mu \mathrm{m}$, original magnification $\times 6000$ ). Data are expressed as the mean $\pm \mathrm{SD}, \mathrm{n}=10$ for serum biochemical parameters and light microscopy, and $\mathrm{n}=3$ for electron microscopy; ${ }^{* *} \mathrm{p}<0.01$ for the comparison with the vehicle + ANIT group; ${ }^{*} \mathrm{p}<0.05$, ${ }^{\# \#}<0.01$ for the comparison with the vehicle group. 
mice, CBP treatment decreased the hepatic levels of hydrophobic BAs, such as deoxycholic acid (DCA), lithocholic acid (LCA), taurodeoxycholic acid (TDCA), and taurolithocholic acid (TLCA), and increased the hydrophilic BAs, such as UDCA and tauroursodeoxycholic acid (TUDCA; Figure 4). Levels of TCDCA and CDCA were also increased in the livers of cholestatic mice. Additionally, CBP treatment significantly increased the total biliary and fecal BA concentrations (Figure 3). Moreover, CBP treatment significantly increased the liver levels of UDCA, CDCA, TCDCA, and TUDCA in normal mice (Supplementary Figure 5).

\section{CBP increases expression of FXR, BA transporters, and metabolic enzymes in cholestatic mice}

As shown in Figure 5A-5D and 5G, CBP treatment markedly increased the mRNA and protein expression of FXR in the livers of mice with ANIT-induced cholestasis.
A a

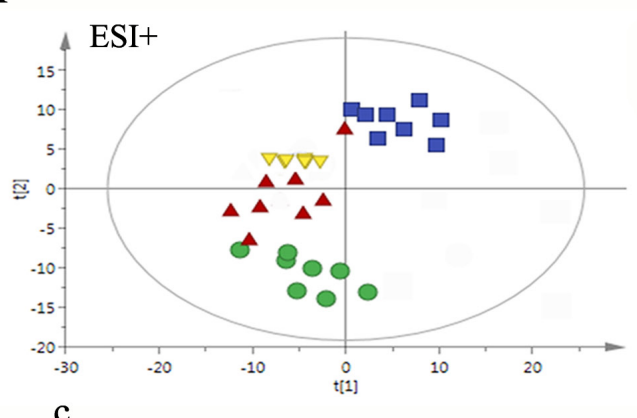

c

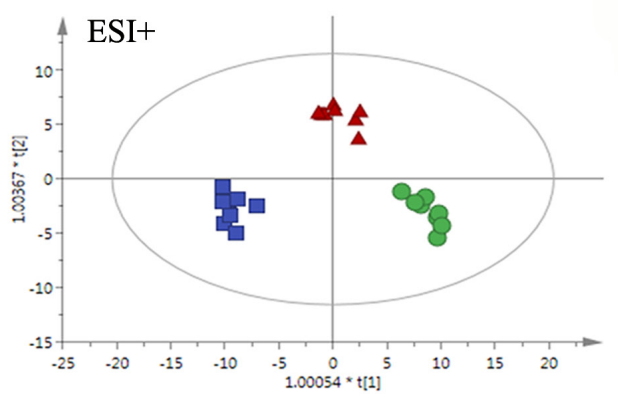

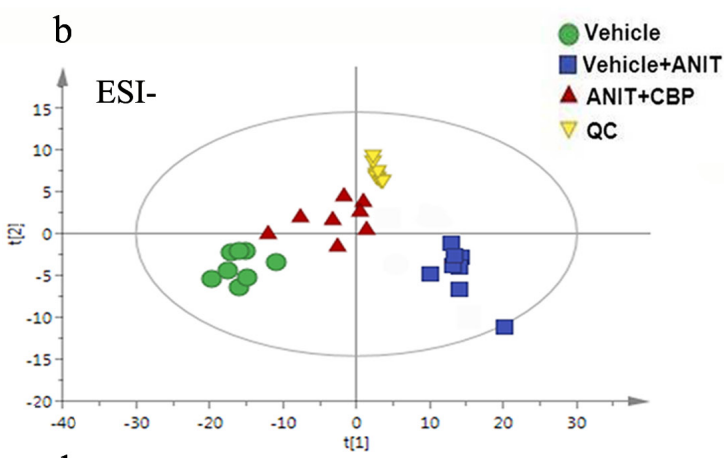

d

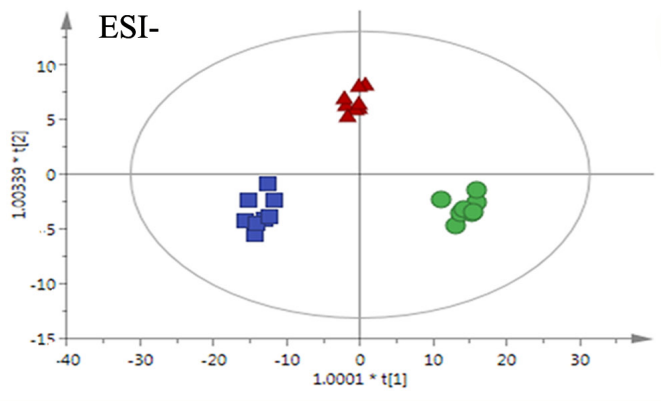

B

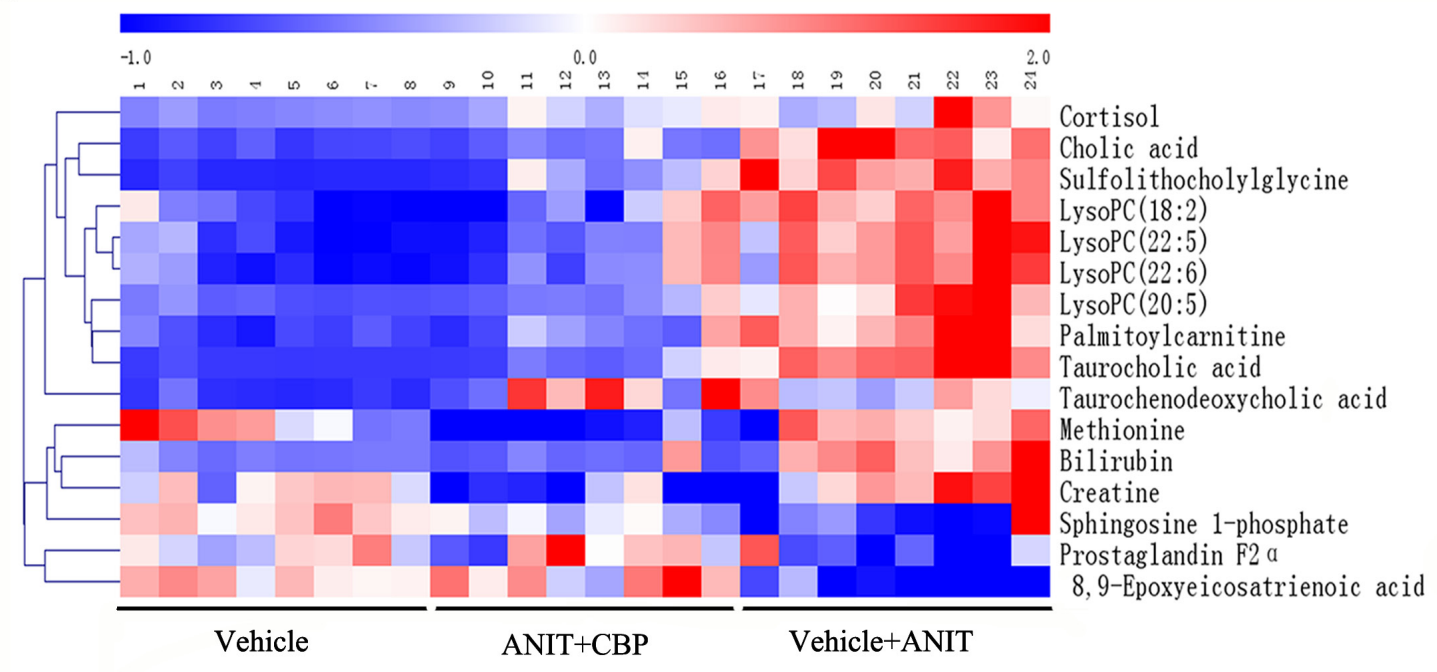

Figure 2: Metabolomics study of CBP in mice with intrahepatic cholestasis. (A-a) PCA score plot in positive ion mode, $\mathrm{R}^{2} \mathrm{X}=0.94, \mathrm{Q}^{2}=0.835$; (A-b) PCA score plot in negative ion mode, $\mathrm{R}^{2} \mathrm{X}=0.942, \mathrm{Q}^{2}=0.792$. (A-c) OPLS-DA score plot in positive ion mode, $R^{2} X=0.9, R^{2} Y=0.947, Q^{2}=0.851$; (A-d) OPLS-DA score plot in negative ion mode. $R^{2} X=0.852, R^{2} Y=0.967, Q^{2}=0.849$. (B) Hierarchical clustering heat map of the metabolites with differential levels in the vehicle, ANIT $+\mathrm{CBP}$, and vehicle+ANIT groups. 
Table 1: Endogenous metabolites identified in the serum of mice included in this study

\begin{tabular}{|c|c|c|c|c|c|c|c|}
\hline VIP & $\begin{array}{l}\text { Time } \\
(\mathrm{min})\end{array}$ & $\begin{array}{l}\text { Molecular } \\
\text { ion }\end{array}$ & $\begin{array}{c}\text { Compound } \\
\text { MW }\end{array}$ & MZ & Formula & Metabolites & HMDB \\
\hline 1.2371 & 0.87 & {$[\mathrm{M}+\mathrm{H}]^{+}$} & 131.0688 & 132.0761 & $\mathrm{C}_{4} \mathrm{H}_{9} \mathrm{~N}_{3} \mathrm{O}_{2}$ & Creatine* & 00064 \\
\hline 1.9915 & 0.95 & {$[\mathrm{M}+\mathrm{H}]^{+}$} & 149.0503 & 150.0575 & $\mathrm{C}_{5} \mathrm{H}_{11} \mathrm{NO}_{2} \mathrm{~S}$ & Methionine* & 00696 \\
\hline 3.9315 & 3.77 & {$[\mathrm{M}+\mathrm{H}]^{+}$} & 515.2887 & 516.2960 & $\mathrm{C}_{26} \mathrm{H}_{45} \mathrm{NO}_{7} \mathrm{~S}$ & Taurocholic acid* & 00036 \\
\hline 2.6512 & 3.91 & {$[\mathrm{M}-\mathrm{H}]^{-}$} & 513.2745 & 512.2678 & $\mathrm{C}_{26} \mathrm{H}_{43} \mathrm{NO}_{7} \mathrm{~S}$ & Sulfolithocholylglycine & 02639 \\
\hline 2.3625 & 4.40 & {$[\mathrm{M}+\mathrm{H}]^{+}$} & 362.2077 & 363.2149 & $\mathrm{C}_{21} \mathrm{H}_{30} \mathrm{O}_{5}$ & Cortisol & 00063 \\
\hline 1.5510 & 4.41 & {$[\mathrm{M}-\mathrm{H}]^{-}$} & 362.2084 & 361.2015 & $\mathrm{C}_{21} \mathrm{H}_{30} \mathrm{O}_{5}$ & Cortisol & 00063 \\
\hline 1.9255 & 4.58 & {$[\mathrm{M}-\mathrm{H}]^{-}$} & 408.2865 & 407.2794 & $\mathrm{C}_{24} \mathrm{H}_{40} \mathrm{O}_{5}$ & Cholic acid* & 00619 \\
\hline 3.1122 & 4.93 & {$[\mathrm{M}+\mathrm{H}]^{+}$} & 584.2606 & 585.2679 & $\mathrm{C}_{33} \mathrm{H}_{36} \mathrm{~N}_{4} \mathrm{O}_{6}$ & Bilirubin* & 00054 \\
\hline 3.7841 & 5.04 & {$[\mathrm{M}+\mathrm{H}]^{+}$} & 499.2948 & 500.3046 & $\mathrm{C}_{26} \mathrm{H}_{45} \mathrm{NO}_{6} \mathrm{~S}$ & Taurochenodeoxycholic acid* & 00951 \\
\hline 1.2292 & 5.46 & {$[\mathrm{M}-\mathrm{H}]^{-}$} & 354.2397 & 353.2335 & $\mathrm{C}_{20} \mathrm{H}_{34} \mathrm{O}_{5}$ & Prostaglandin F $2 \alpha^{*}$ & 01139 \\
\hline 1.4079 & 6.92 & {$[\mathrm{M}+\mathrm{H}]^{+}$} & 379.2470 & 380.2542 & $\mathrm{C}_{18} \mathrm{H}_{38} \mathrm{NO}_{5} \mathrm{P}$ & Sphingosine 1-phosphate & 00277 \\
\hline 1.0619 & 6.92 & {$[\mathrm{M}-\mathrm{H}]^{-}$} & 379.2477 & 378.2406 & $\mathrm{C}_{18} \mathrm{H}_{38} \mathrm{NO}_{5} \mathrm{P}$ & Sphingosine 1-phosphate & 00277 \\
\hline 2.3307 & 7.10 & {$[\mathrm{M}+\mathrm{H}]^{+}$} & 541.3142 & 542.3215 & $\mathrm{C}_{28} \mathrm{H}_{48} \mathrm{NO}_{7} \mathrm{P}$ & LysoPC(20:5) & 10397 \\
\hline 1.4450 & 7.54 & {$[\mathrm{M}+\mathrm{H}]^{+}$} & 519.3282 & 520.3354 & $\mathrm{C}_{26} \mathrm{H}_{50} \mathrm{NO}_{7} \mathrm{P}$ & LysoPC(18:2) & 10386 \\
\hline 1.5763 & 7.67 & {$[\mathrm{M}+\mathrm{H}]^{+}$} & 567.3278 & 568.3351 & $\mathrm{C}_{30} \mathrm{H}_{50} \mathrm{NO}_{7} \mathrm{P}$ & LysoPC(22:6) & 10404 \\
\hline 1.8473 & 7.97 & {$[\mathrm{M}+\mathrm{H}]^{+}$} & 569.3453 & 570.3525 & $\mathrm{C}_{30} \mathrm{H}_{52} \mathrm{NO}_{7} \mathrm{P}$ & LysoPC(22:5) & 10403 \\
\hline 1.5650 & 8.40 & {$[\mathrm{M}-\mathrm{H}]^{-}$} & 320.2344 & 319.2276 & $\mathrm{C}_{20} \mathrm{H}_{32} \mathrm{O}_{3}$ & 8,9-Epoxyeicosatrienoic acid & 02232 \\
\hline 1.5343 & 8.61 & {$[\mathrm{M}+\mathrm{H}]^{+}$} & 399.3314 & 400.3387 & $\mathrm{C}_{23} \mathrm{H}_{45} \mathrm{NO}_{4}$ & L-Palmitoylcarnitine & 00222 \\
\hline
\end{tabular}

* Identified by authenticated standard.

Treatment with CBP for 14 days had slightly increased the FXR protein expression in normal mice (Supplementary Figure 6). Additionally, CBP treatment also has no influence on the protein expression of FXR in mice that induced by ANIT at 24h (Supplementary Figure 7). The
BA efflux transporter, Bsep, which is the main target gene of FXR, also showed significantly elevated protein expression in the livers of cholestatic mice treated with CBP (Figure 5G). Moreover, as shown in Figure 5E$5 \mathrm{G}, \mathrm{CBP}$ administration significantly increased the liver
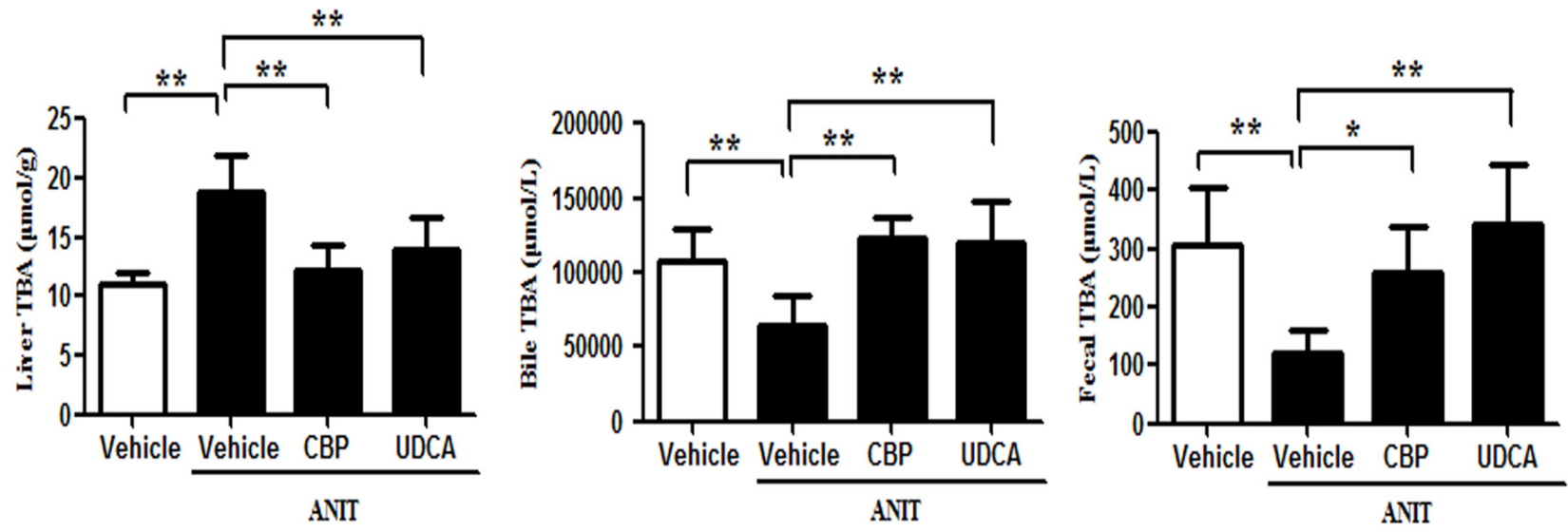

Figure 3: CBP decreases the liver, bile, and fecal total BA levels in mice with intrahepatic cholestasis. Data are expressed as the mean $\pm \mathrm{SD}, \mathrm{n}=10 ;{ }^{*} \mathrm{p}<0.05,{ }^{* *} \mathrm{p}<0.01$ for the comparison with the vehicle+ANIT group. 
protein expression of multidrug resistance-associated protein (Mrp) 2, and prevented the ANIT-induced decrease in Mrp2 mRNA expression (Figure 5H). Notably, CBP treatment also significantly increased hepatic expression of Mrp3 protein (Figure 5G), and the expression of Mrp3 and Mrp4 mRNAs (Figure 5I-5J). In addition to affecting BA transporters, CBP treatment markedly increased liver expression of mRNAs encoding a BA hydroxylation enzyme (cytochrome P450 [Cyp] 2b10) and conjugation enzyme (UDP-glucuronosyltransferase 1A1 [Ugtla1]) in cholestatic mice (Figure 5K-5L).

\section{CBP inhibits expression of hepatic inflammatory factors in cholestatic mice}

Metabolomics analysis showed that CBP treatment significantly increased the serum level of 8 , 9-epoxyeicosatrienoic acid (Figure 6), as compared with the ANIT-induced cholestatic group. Additionally, as shown in Figure 6, the hepatic protein levels of inhibitor of kappa B kinase (IKK) $\alpha$ and NF- $\kappa$ B were significantly higher in the ANIT-induced cholestatic group than in the vehicle group, while inhibitor of kappa $\mathrm{B} \alpha(\mathrm{I} \kappa \mathrm{B} \alpha)$ protein
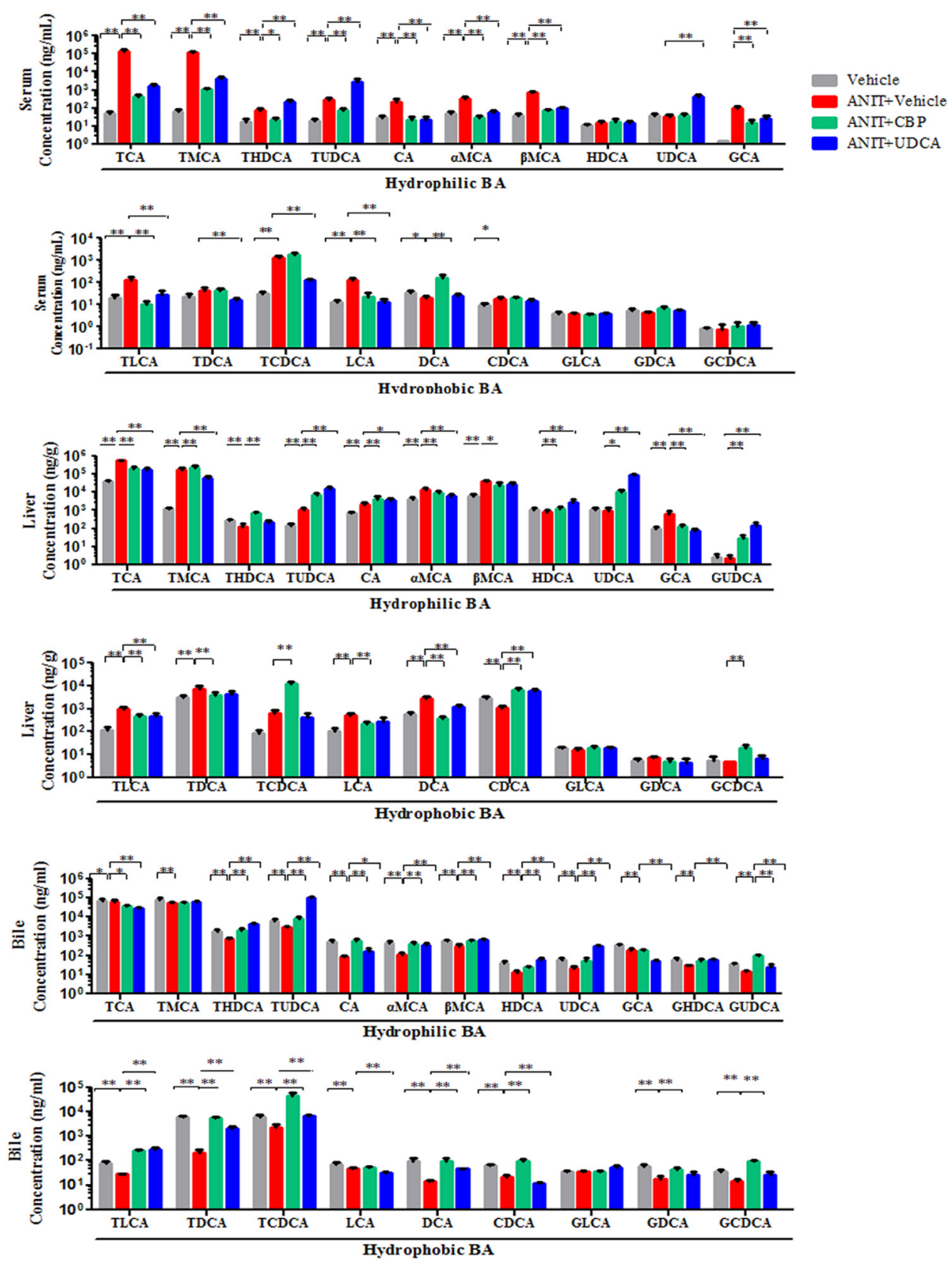

Figure 4: The influence of CBP on hydrophilic and hydrophobic BAs detected by UPLC-MS/MS in mice with intrahepatic cholestasis. Data are expressed as the mean $\pm \mathrm{SD}, \mathrm{n}=10 ;{ }^{*} \mathrm{p}<0.05,{ }^{* *} \mathrm{p}<0.01$ for the comparison with the vehicle+ANIT group. 
expression was decreased (Figure 6). Moreover, the liver levels of inflammatory factors such as interleukin-1 (IL1) and intercellular adhesion molecule-1 (ICAM-1) were markedly increased in the ANIT-induced cholestatic group. However, treatment with CBP markedly decreased the expression of NF- $\kappa \mathrm{B}$ and IKK $\alpha$ proteins, and increased the I $\mathrm{B} \alpha \alpha$ protein level. Notably, treatment with CBP significantly reduced the liver expression of IL-1 and ICAM-1 in cholestatic mice (Figure 6).

\section{CBP induces FXR activation in $\mathrm{Na}^{+}$-taurocholate cotransporting polypeptide (Ntcp)-transfected human embryonic kidney (HEK293T) cells}

As shown in Figure 7, we performed dual luciferase assays to assess which components in CBP acted directly on the FXR. HEK293T cells were transfected with FXR, retinoid X receptor, and pRL-SV40 expression plasmids, in the presence or absence of a recombinant Ntcp (rNtcp) expression vector. Exposure to CDCA, UDCA, or cholic acid (CA) at $20 \mu \mathrm{M}$ significantly induced FXR activity by 13-, 8-, and 3-fold in HEK293T cells, respectively (Figure 7A). However, CBP, TCDCA, TUDCA, and TCA did not produce this effect. Additionally, TCDCA and CBP both induced greater than 2-fold activation of FXR in rNtcpHEK293T cells (Figure 7B). Moreover, TUDCA, TCDCA, and CBP concentration-dependently increased FXR activity in rNtcp-HEK293T cells (Figure 7C). To verify the source of this FXR activation effect, we performed separate quantitative analyses of BAs in the cytoplasm and nucleus. TUDCA, TCDCD, and TCA were detected in the cytoplasm and nucleus, whereas it was hard to detect UDCA, CDCA, and CA in rNtcp-HEK293T cells treated with TUDCA, TCDCD, or TCA, respectively (Figure 7D and Supplementary Table 6). Moreover, in rNtcp-HEK293T cells treated with CBP, TCDCA and TCA were detectable in the cytoplasm and nucleus, while CDCD and CA were not detected (Figure 7D and Supplementary Table 6).

\section{Effects of CBP on cytoplasmic and nuclear concentrations of BAs in liver tissues of cholestatic mice}

This analysis indicated that UDCA, CDCA, CA, TUDCA, TCDCA, and TCA were all detected in the cytoplasm and nucleus of liver tissues from cholestatic

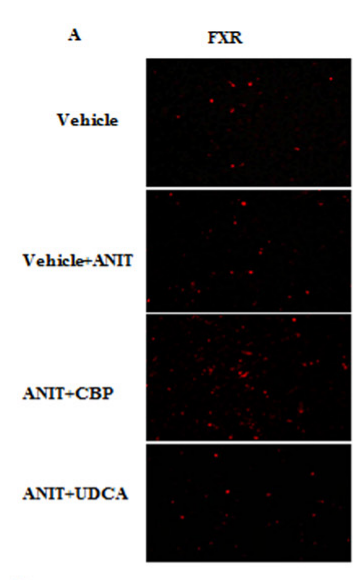

B

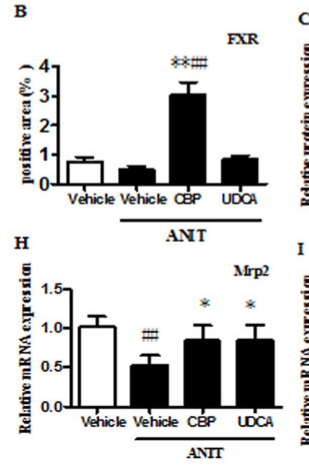

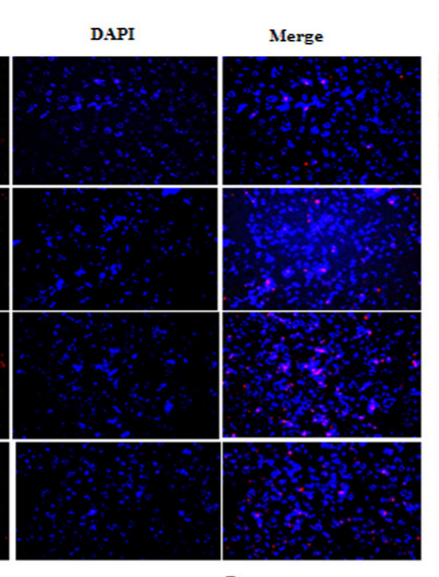
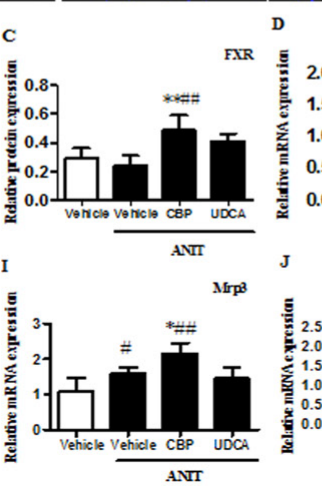
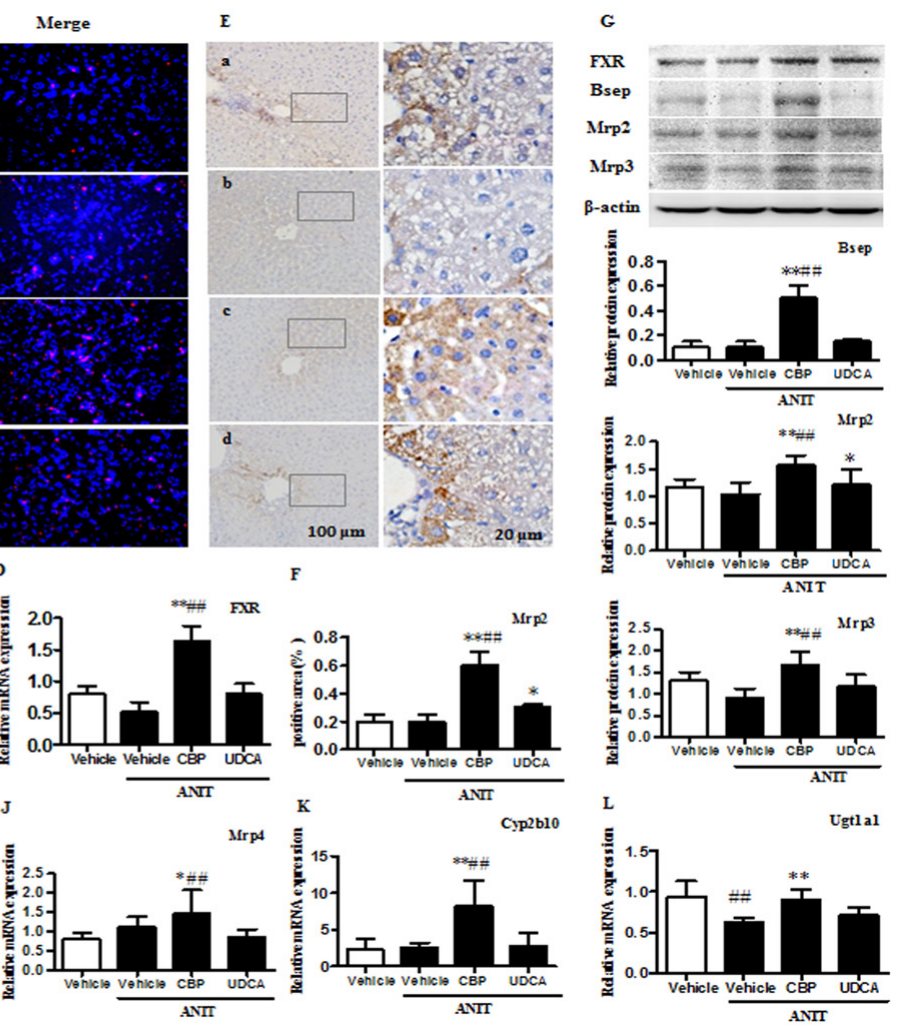

Figure 5: CBP increases expression of FXR, BA transporters, and metabolic enzymes in mice with intrahepatic cholestasis. (A) Effect of CBP on FXR protein expression, detected by immunofluorescence. (B-D) Quantitative analysis of liver FXR expression, detected by immunofluorescence, western blot, and real-time PCR. (E-F) Effect of CBP on liver expression of Mrp2, detected by immunohistochemistry. (G) Effect of CBP on FXR, Bsep, Mrp2, and Mrp3 protein expression, detected by western blot. (H-L) Effect of CBP on Mrp2, Mrp3, Mrp4, Cyp2b10, and Ugt1a1 mRNA levels, detected by real-time PCR. Data are expressed as the mean \pm SD, ${ }^{*} p<$ $0.05,{ }^{* *} \mathrm{p}<0.01$ for the comparison with the vehicle+ANIT group; ${ }^{\#} \mathrm{p}<0.05,{ }^{\#} \mathrm{p}<0.01$ for the comparison with the vehicle group. 
mice treated with CBP (Figure 7E). The nuclear concentrations of CDCA, UDCA, TCDCA, and TUDCA were significantly higher in cholestatic mice treated with $\mathrm{CBP}$, as compared with those treated with ANIT alone.

\section{Effects of CBP ingredients on ANIT-induced intrahepatic cholestasis in mice}

As shown in Supplementary Figure 9, as compared with mice treated with ANIT alone, pretreatment with TCDCA significantly decreased the ANIT-induced increases in ALT, AST, $\gamma$-GT, TBA, TBIL, and DBIL in cholestatic mice. TCA could only decrease the increased levels of AST, TC, TBA, TBIL, and DBIL induced by ANIT, and had no influence on the ALT and $\gamma$-GT levels (Supplementary Figure 9).

\section{Effects of CBP on ANIT-induced intrahepatic cholestasis in FXR-knockout (FXRKO) mice}

As compared with the control group, the levels of ALT, AST, ALP, $\gamma$-GT, TC, TBA, TBIL, and DBIL were significantly increased in ANIT-induced cholestatic FXRKO mice. Treatment with CBP had no inhibitory effects on the ANIT-induced increases in these biochemical markers in cholestatic FXRKO mice (Figure 8A). In addition, hematoxylin-eosin staining identified acute inflammatory cell infiltration, edema, and hepatic necrosis in the livers of ANIT-induced cholestatic FXRKO mice, as compared with the control tissue, and CBP treatment did not ameliorate these changes (Figure 8B). These observations implied that CBP could not ameliorate ANIT-induced intrahepatic cholestasis in FXRKO mice.

\section{DISCUSSION}

The use of bear's bile is limited by availability and ethical concerns and it is therefore important to explore whether other natural products could be used to treat liver disorders. However, the effects of CBP on intrahepatic cholestatic liver disease had not been characterized prior to the present study. In recent years, mouse models have been used to evaluate the efficacy of traditional medicines [29-32]. In the current study, a mouse model of ANIT-
A
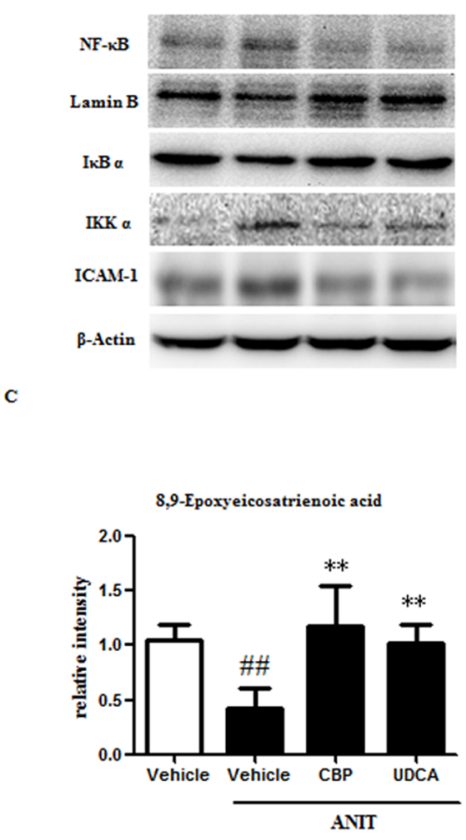

B
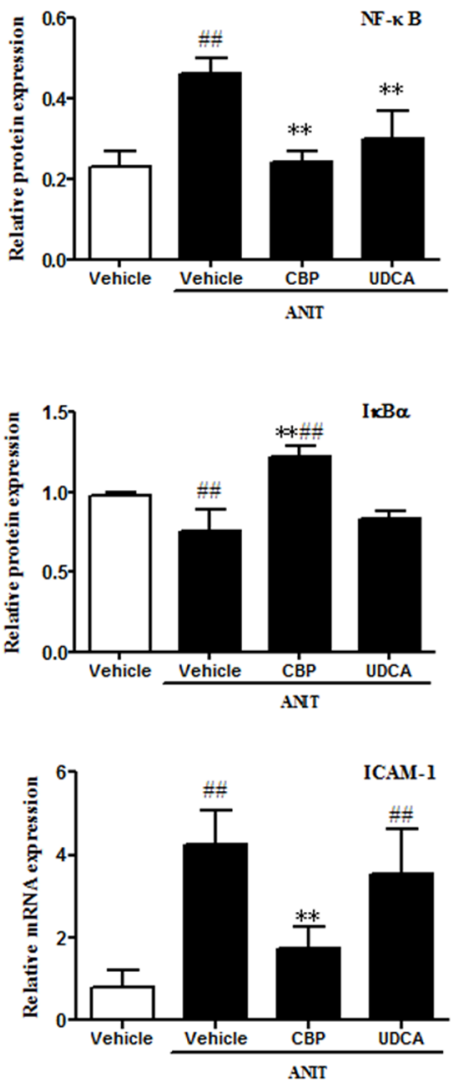

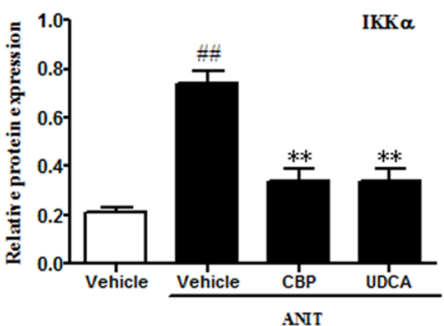

ICAM-1
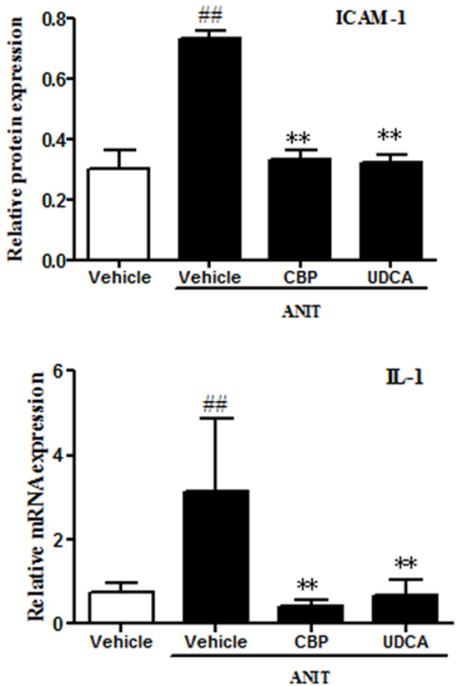

Figure 6: CBP inhibits liver inflammation in mice with intrahepatic cholestasis. (A) The effects of CBP on protein levels of

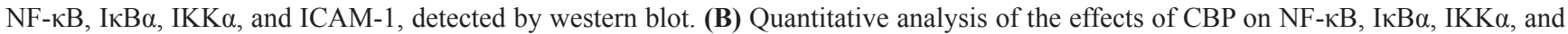
ICAM-1 proteins, and IL-1 and ICAM-1 mRNA expression. (C) Quantitative analysis of 8, 9-epoxyeicosatrienoic acid by UPLC-LTQorbitrap. Data are expressed as the mean $\pm \mathrm{SD},{ }^{*} \mathrm{p}<0.05,{ }^{* *} \mathrm{p}<0.01$ for the comparison with the vehicle+ANIT group; ${ }^{\#} \mathrm{p}<0.05,{ }^{\# \#} \mathrm{p}<0.01$ for the comparison with the vehicle group. 
induced intrahepatic cholestasis was used to investigate the effects of CBP on cholestatic liver injury. The present results found that CBP administration ameliorated ANITinduced damage to liver histology and function, indicating that it has the potential to protect against cholestatic liver injury.

Metabolomic studies analyze the holistic and dynamic nature of biological systems, which is consistent with the core theory of holism and syndrome differentiation in traditional Chinese medicine [33, 34]. Therefore, metabolomics can help to clarify the metabolic pathways and mechanisms of action of traditional Chinese medicines [35-37]. In the present study, serum metabolomics found that BA biosynthesis and arachidonic acid metabolism were the two most important metabolic pathways that were influenced by CBP. This result
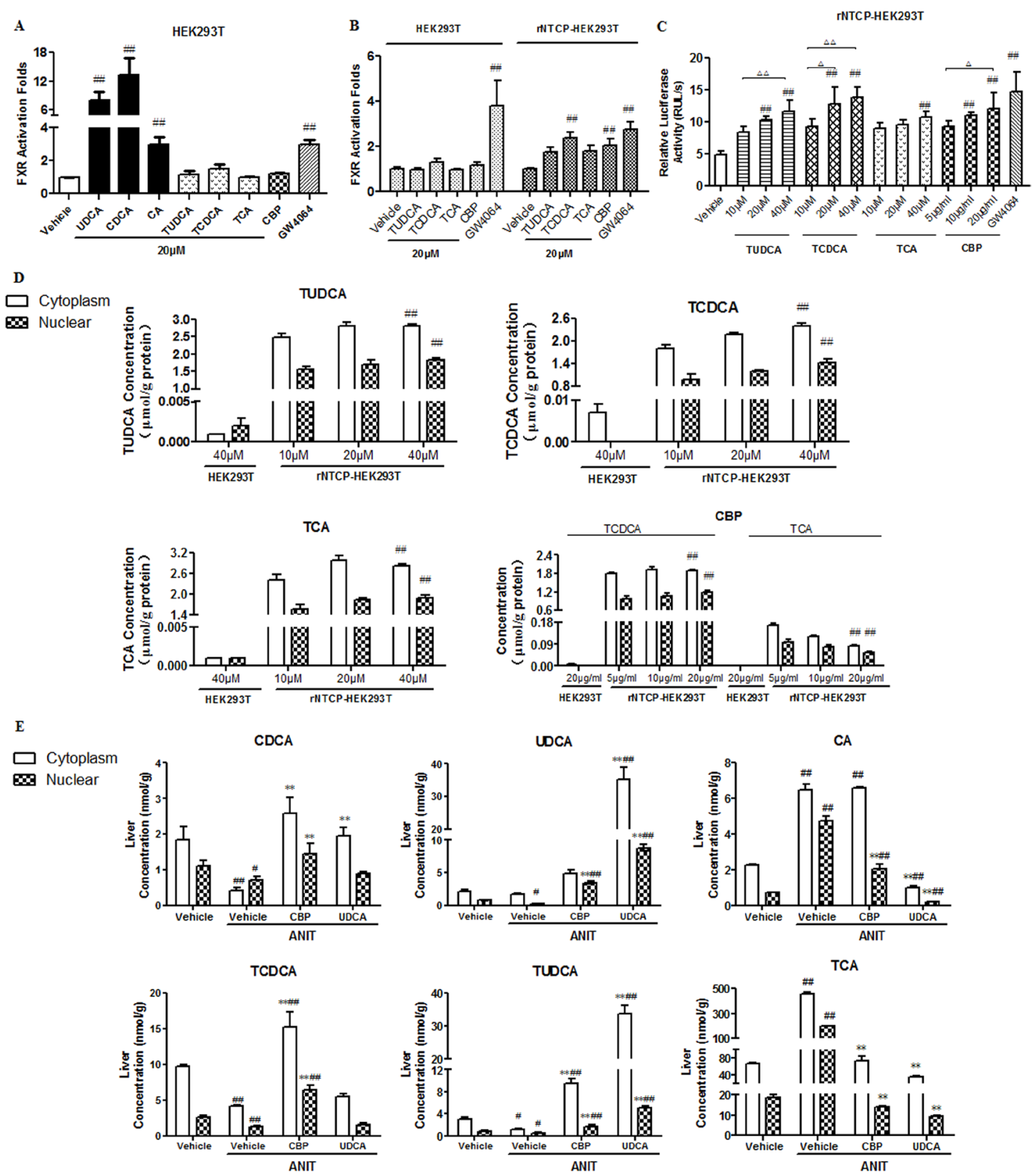

Figure 7: CBP promotes FXR activation in rNtcp-HEK293T cells and alters BA concentrations in rNtcp-HEK293T cells and mouse liver. The effects of the indicated treatments on FXR activation in (A) HEK293T cells and (B, C) rNtcp-HEK293T cells. Data are expressed as the mean $\pm \mathrm{SD}, \mathrm{n}=5$; ${ }^{*} \mathrm{p}<0.05,{ }^{* \#} \mathrm{p}<0.01$ for the comparison with the vehicle group. (D) The cytoplasmic and nuclear BA concentrations in HEK293T and rNtcp-HEK293T cells exposed to the indicated treatments. Data are expressed as the mean \pm SD, $\mathrm{n}=3$; ${ }^{\#} \mathrm{p}<0.05,{ }^{\#} \mathrm{p}<0.01$ for the comparison with the HEK293T cells $(20 \mu \mathrm{g} / \mathrm{ml}$ treatments). (E) Cytoplasmic and nuclear BA concentrations in the livers of mice with intrahepatic cholestasis following treatment with CBP for two weeks. Data are expressed as the mean $\pm \mathrm{SD}, \mathrm{n}=3$; ${ }^{*} \mathrm{p}<0.05,{ }^{* *} \mathrm{p}<0.01$ for the comparison with the vehicle+ANIT group; ${ }^{*} \mathrm{p}<0.05,{ }^{\#} \mathrm{p}<0.01$ for the comparison with the vehicle group. 
suggested that the potential mechanism of action of CBP against intrahepatic cholestasis may associate with its influence on BA homeostasis and inflammation.

Overall, treatment with CBP ameliorated the high serum and liver levels of TBA found in the ANIT-treated mice and increased their biliary and fecal BA excretion. In addition, CBP administration decreased hepatocyte concentrations of toxic hydrophobic BAs such as DCA and LCA, which may aggravate hepatic apoptosis and necrosis [14, 15], and increased the levels of hydrophilic BAs such as UDCA and TUDCA, thus beneficially improving the hepatic BA composition. BAs are synthesized from cholesterol in the liver via reactions that are mainly catalyzed by Cyp7a1 and Cyp8b1. The current study identified reduced liver expression of Cyp7a1 and Cyp8b1 (Supplementary Figure 8), and increased liver cholesterol levels in ANIT-induced cholestatic mice, which may reflect intrahepatic BA retention. However, CBP treatment decreased the intrahepatic retention of BAs and reversed the effects of ANIT on liver Cyp7a1 and Cyp8b1 expression. Moreover, in the current study, CBP treatment induced the liver expression of Cyp2b10, Ugt1a1, and BA efflux transporters (Mrp2, Bsep, Mrp3, and Mrp4). These results suggested that CBP could increase the expression of specific BA metabolizing enzymes and efflux transporters, thereby promoting the detoxification and excretion of hepatotoxic BAs, thus reversing the disordered homeostasis of BAs.

Accumulation of toxic BAs has been reported to induce the production of inflammatory cytokines [38]. The present study observed decreased levels of epoxyeicosatrienoic acid in the ANIT-induced mouse liver. This metabolite of arachidonic acid has been reported to exert anti-inflammatory effects via a NF- $\kappa \mathrm{B}-$ mediated mechanism [39-41]. In the current study, CBP treatment enhanced the serum level of 8, 9-epoxyeicosatrienoic acid in cholestatic mice, indicating that it may produce antiinflammatory effects. Additional morphological analyses observed inflammatory cell infiltration in the livers of cholestatic mice, and indicated that this was relieved by CBP treatment. Moreover, CBP treatment effectively decreased the liver expression of NF- $\kappa B$, IKK $\alpha$, ICAM1 , and IL- 1 proteins, and increased $\mathrm{I} \kappa \mathrm{B} \alpha$ expression in cholestatic mice. The present results suggested that the alleviation of NF- $\mathrm{NB}-$ mediated inflammation played an important role in the protective effect of CBP against cholestatic liver injury.

$A$
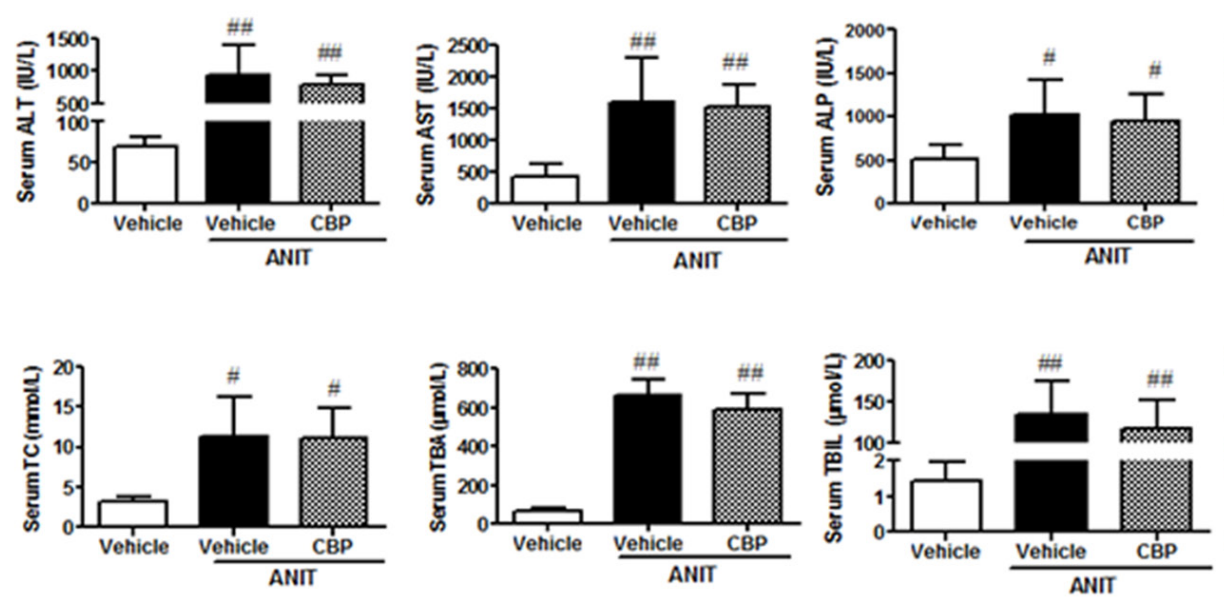

B

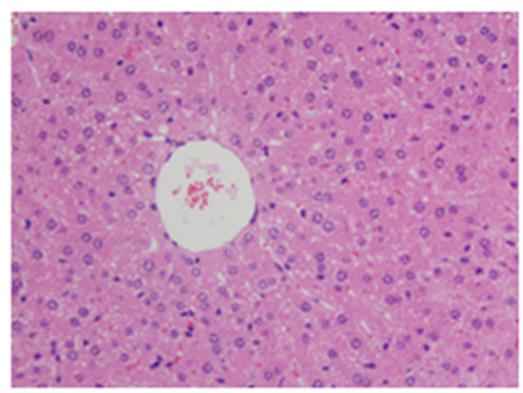

Vehicle

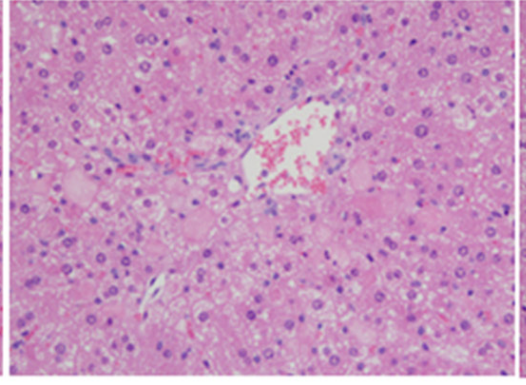

Vehicle+ ANIT
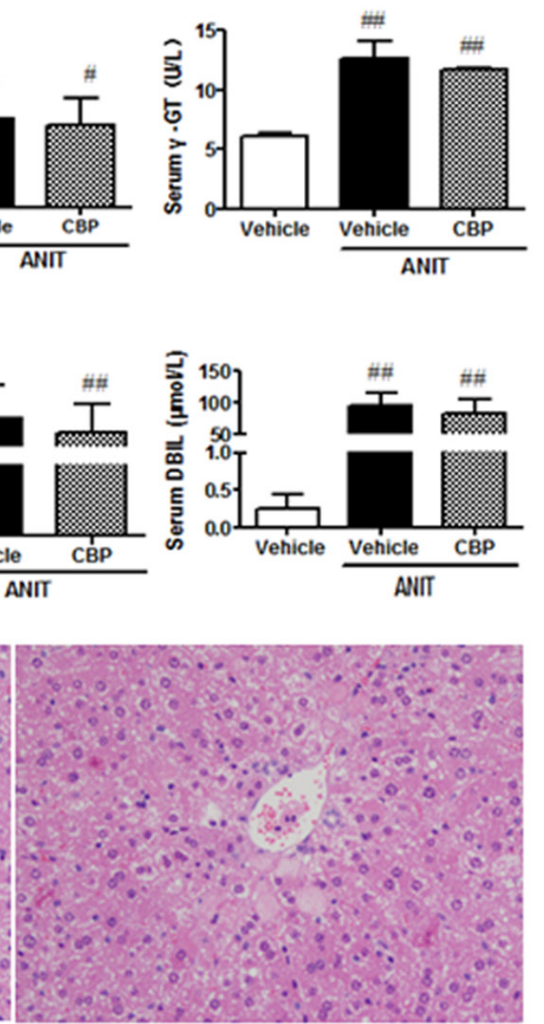

ANIT + CBP

Figure 8: Effects of CBP on ANIT-induced intrahepatic cholestasis in FXRKO mice. (A) Serum biochemical parameters. (B) Liver morphology was observed by light microscopy (original magnification $\times 200$ ). Data are expressed as the mean $\pm \mathrm{SD}, \mathrm{n}=4$; $\# \mathrm{p}<0.05$, ${ }^{\#} \mathrm{p}<0.01$ for the comparison with the vehicle group. 
FXR is an important BA-activated nuclear receptor that can modify cholestatic liver injury $[42,43]$. FXR activation can also inhibit NF- $\kappa B$ pathway-mediated inflammation [44, 45]. Our current results found that CBP treatment induced hepatic FXR expression, promoted expression of its downstream genes (Bsep, Mrp2, and Ugt1a1), reversed disordered BA homeostasis, inhibited NF- $\mathrm{kB}$ mediated inflammation, and finally reduced cholestatic liver injury. Additionally, luciferase assays conducted in rNtcp-HEK293T cells revealed that $\mathrm{CBP}$ could concentration-dependently increase FXR activity. Therefore, we used FXRKO mice to investigate whether the protective effects of CBP against cholestatic liver injury in FXR-dependent. Our findings indicated that CBP could not ameliorate the intrahepatic cholestasis induced by ANIT in FXRKO mice. Taken together, these results suggested that CBPmediated protection from cholestatic liver injury was FXR-dependent.

In this study, treatment with CBP increased the liver levels of UDCA, TUDCA, CDCA, and TCDCA in cholestatic mice. To investigate the effect of CBP ingredients (TCDCA and TCA) as well as metabolites (TUDCA, UDCA, CDCA and CA) on FXR activity, luciferase assays were conducted using HEK293T cells and rNtcp-HEK293T cells. The results indicated that (except for CDCA), UDCA also activated FXR in HEK293T cells. Additionally, TCDCA, TUDCA, and CBP all activated FXR in rNtcp-HEK293T cells. Quantitation of hepatic cytoplasmic and nuclear BAs revealed that non-conjugated BAs were not detected in rNtcp-HEK293T cells, further confirming the direct effect of TCDCA and TUDCA on FXR. Furthermore, the nuclear concentrations of CDCA, UDCA, TCDCA, and TUDCA were all increased in the livers of cholestatic mice treated with CBP. Taken together, these findings suggested that after treatment with CBP, TCDCA and its derivatives (CDCA, UDCA, and TUDCA) could all activate FXR.

In order to illuminate the effective components of CBP against cholestatic liver injury in vivo, the effects of TCDCA and TCA (equivalent to the amounts in 0.2 $\mathrm{g} / \mathrm{kg}$ CBP) on ANIT-treated mice were investigated. These results showed that TCDCA improved more of the biochemical indicators than TCA. Therefore, TCDCA may be largely responsible for the effects of CBP on ANITinduced cholestatic liver injury. Additionally, treatment with CBP significantly increased the level of UDCA in the liver and bile of cholestatic mice, but not in the serum. The reasons for this phenomenon may include the following. Firstly, intestinal microbial enzymes have been reported to catalyze the conversion of TCDCA to CDCA, and then to UDCA [46-49], which can be absorbed by hepatocytes. The proportion of TCDCA in CBP was 74\% and this treatment may therefore significantly increase the liver level of UDCA. Secondly, CBP treatment markedly increased the liver expression of BA efflux transporters (Bsep and Mrp2). This could enhance biliary BA excretion, which is the major efflux route for hepatic BAs. Therefore, the increased level of UDCA in the liver could be excreted into bile. This would mean that the serum UDCA level would not change significantly, even though CBP slightly increased the BA efflux transporters, Mrp3 and Mrp4. Additionally, increased liver level of CDCA and an increasing trend of FXR expression were found in normal mice after treated with CBP. But CBP had no influence on liver function of normal mice. The reason for this phenomenon may be due to that the bile acid homeostasis is well regulated and controlled in normal mice. However, this is still needed to investigate in the future.

High concentrations of hydrophobic BAs are potentially hepatotoxic and CDCA was reported to significantly reduce cell viability at concentrations above $50 \mu \mathrm{M}$, while TCDCA required a higher concentration $(250 \mu \mathrm{M})$ to produce this effect $[50,51]$. The current research found that the liver concentrations of both CDCA and TCDCA (16.6 and $25.8 \mathrm{nmol} / \mathrm{g}$ liver) after CBP treatment were far below these cytotoxic concentrations. Our results identified marked increases in the liver levels of UDCA and TUDCA after CBP treatment, which might be derived from the TCDCA following catalysis by intestinal microbial enzymes. However, further research is required to determine the exact biotransformations of BAs following treatment with CBP. Additionally, results from metabolomic studies revealed that CBP and UDCA shared 15 metabolites (Supplementary Table 5 and Supplementary Figure 4). However, there were also some metabolic differences between the two groups, indicating that CBP and UDCA may act via some different mechanisms, which should be explored in the future.

In conclusion, our data highlight the protective effects of CBP in intrahepatic cholestasis and liver injury. The mechanism underlying the effects of CBP involves increasing FXR activation and expression, reversing the disordered homeostasis of BAs, and alleviating liver inflammation. The present results indicated that CBP may provide a natural source for the treatment of intrahepatic cholestasis.

\section{MATERIALS AND METHODS}

\section{Chemicals and reagents}

ANIT, carbamazepine, mycophenolic acid, and reference standards for $18 \mathrm{BAs}$, including CA, glycocholic acid, TCA, CDCA, glycochenodeoxycholic acid, TCDCA, deoxycholic acid, glycodeoxycholic acid, taurodeoxycholic acid, UDCA, glycoursodeoxycholic 
acid, TUDCA, LCA, glycolithocholic acid, taurolithocholic acid, hyodeoxycholic acid, glycohyodeoxycholic acid, and taurohyodeoxycholic acid were purchased from Sigma-Aldrich (St. Louis, MO, USA). Chromatography-grade acetonitrile was purchased from Merck (Darmstadt, Germany). Water was purified using a MilliQ water system (Millipore, Bedford, MA, USA). Chromatography-grade acetic acid, formic acid, and methanol were provided by Tedia Company (Fairfield, OH, USA).

\section{Preparation and composition analysis of CBP}

CBP (batch number: SJ141101) was prepared and supplied by Kai Bao Pharmaceutical Co. (Shanghai, China). Briefly, chicken bile was filtered and centrifuged. The supernatant was concentrated and dried to obtain the crude extract, which was dissolved in ethanol. After extraction by ethyl acetate, the aqueous phase was collected, filtered, and dried to produce CBP. The main constituents of CBP were measured by ultra-performance liquid chromatography-quadrupole mass spectrometry (UPLC-MS/MS). The proportions of TCDCA, TCA, CDCA, and CA in CBP were $74,15,2.81$, and $0.45 \%$, respectively.

\section{Animals and experimental design}

Male wild-type C57BL/6 mice (8 weeks old) weighing 18-20 g were provided by the Animal Center of Shanghai University of Traditional Chinese Medicine (SHUTCM, Shanghai, China). FXRKO mice were obtained from UC Davis Medical Center, and reproduced in a SHUTCM animal feeding room. All mice were kept in a room at $22-24^{\circ} \mathrm{C}$, with a light/ dark cycle of $12 / 12 \mathrm{~h}$ and $55-60 \%$ relative humidity, with free access to standard rodent food and water. All animal experimental procedures were approved by the Committee on the Use of Live Animals for Teaching and Research of the Shanghai University of Traditional Chinese Medicine (Approval Number: 20150401), and all experiments were performed in accordance with the guidelines of this committee.

For animal experiment 1, 40 wild-type mice were randomly assigned to 4 groups: vehicle group, vehicle+ANIT group, ANIT+CBP group $(0.2 \mathrm{~g} / \mathrm{kg}$, i.g. $)$, and ANIT+UDCA group (115 mg/kg, i.g.). For animal experiment 2, 12 FXRKO mice were divided into 3 groups: vehicle group, ANIT-treated group, and ANIT-treated group that was pretreated with $\mathrm{CBP}(0.2 \mathrm{~g} / \mathrm{kg}$, i.g.). For animal experiment 3, 70 wild-type mice were randomly assigned to 7 groups: vehicle group, vehicle+ANIT group, ANIT + CBP groups that were pretreated with low $(0.05$ $\mathrm{g} / \mathrm{kg}$, i.g.), middle ( $0.1 \mathrm{~g} / \mathrm{kg}$, i.g.), or high $(0.2 \mathrm{~g} / \mathrm{kg}$, i.g.) doses of CBP, ANIT+TCDCA group (148 mg/kg, i.g.), and ANIT+TCA group (30 mg/kg, i.g.). The drugs were administered to the mice for 14 days, and ANIT (dissolved in corn oil; $50 \mathrm{mg} / \mathrm{kg}$, i.g.) was administered on the $12^{\text {th }}$ day. Forty-eight hours after ANIT treatment, serum and liver tissue samples were obtained, snap-frozen in liquid nitrogen, and stored at $-80^{\circ} \mathrm{C}$ until use.

\section{Serum biochemistry and hematoxylin-eosin staining}

Serum activities of ALT, AST, and ALP, and serum TBA, TBIL, and DBIL were measured using a Hitachi 7080 Chemistry Analyzer (Hitachi Ltd., Tokyo, Japan). The total levels of BAs in the liver, bile, and feces were measured using a commercially available kit (Nanjing Jiancheng Bioengineering Institute, Nanjing, China), in accordance with the manufacturer's instructions. Liver samples were fixed with $4 \%$ paraformaldehyde in phosphate buffer prior to embedding in paraffin. Tenmicrometer sections were stained with hematoxylin and eosin using standard procedures and observed by light microscopy.

\section{Transmission electron microscopy}

Immediately after dissection, liver tissue samples were immersed in $2.5 \%$ glutaraldehyde in $0.1 \mathrm{M}$ cacodylate buffer ( $\mathrm{pH} 7.4$ ) overnight, post-fixed in $2.0 \%$ osmium tetroxide for $2 \mathrm{~h}$, dehydrated through a series of ethanol solutions, and embedded in Epon. Ultrathin sections $(50 \mathrm{~nm})$ of periportal areas, stained with uranyl acetate and lead citrate, were examined under the JEM100CX- $\alpha$ electron microscope (JEOL Ltd., Tokyo, Japan).

\section{Metabolomics study}

\section{Sample preparation}

An aliquot of $20 \mu \mathrm{L}$ serum was deproteinized using $100 \mu \mathrm{L}$ acetonitrile containing internal standards (positive: carbamazepine $20 \mathrm{ng} / \mathrm{mL}$; negative: mycophenolic acid, $320 \mathrm{ng} / \mathrm{mL}$ ). The sample mixture was vortex-mixed for 3 min and then centrifuged at $16000 \mathrm{rpm}$ for $10 \mathrm{~min}$ at $4^{\circ} \mathrm{C}$. QC samples were prepared by combining equal aliquots of all serum samples included in the study, which were processed in the same manner as the other serum samples. The QC samples were analyzed before, during, and after each analysis run.

\section{Instrumentation and operation conditions}

Liquid chromatographic separation was performed using a UPLC system (Dionex, Thermo Fisher Scientific; Sunnyvale, CA, USA). The analytical column was a Waters ACQUITY UPLC BEH $\mathrm{C}_{18}$ column $(2.1 \mathrm{~mm} \times$ $100 \mathrm{~mm} ; 1.7 \mu \mathrm{m}$ ) (Waters, Co., Milford, MA, USA). The column and automatic sampler were maintained at $35^{\circ} \mathrm{C}$ and $4^{\circ} \mathrm{C}$, respectively, and the injection volume was $5 \mu \mathrm{L}$. 
The gradient elution was $20 \mathrm{~min}$ at a flow rate of $0.3 \mathrm{~mL} /$ min, with mobile phases containing water with $0.1 \%$ formic acid (A) and acetonitrile with $0.1 \%$ formic acid (B). The elution was run on the following schedule: $10 \%$ B from 0.1-2 min; a linear increase from 10-40\% B over 5 min; a linear increase from $40-80 \%$ B over 4 min; a linear increase from $80-90 \%$ B over $4 \mathrm{~min}$; $90 \%$ B for 0.5 min. At $15.5 \mathrm{~min}$, B was adjusted to $10 \%$ and equilibrated for $4.5 \mathrm{~min}$. The UPLC system was connected to an LTQorbitrap elite mass spectrometry system (Thermo Fisher Scientific; Bremen, Germany) via a heated electrospray ionization (ESI) source in both positive and negative ionization mode. The mass spectrometer parameters were as follows: ion spray voltage, $3.8 \mathrm{kV}(+)$ and $3.2 \mathrm{kV}(-)$; capillary and heater temperature, both $350^{\circ} \mathrm{C}$; sheath and auxiliary gas flow rate, 45 and 15 psi; and S-Lens RF level, $60 \%$.

Data processing and standardization of metabolites, identification of potential biomarkers, and metabolic pathway analysis

The data preprocessing and analysis, identification of potential biomarkers, and pathway analysis were performed as previously reported [52].

\section{Quantitation of BAs in serum, liver, and bile}

UPLC-MS/MS was used to detect 18 BAs in mouse serum, liver, and bile. The sample preparation and UPLCMS/MS analyses were performed as described previously $[53,54]$, with slight modification. BA calibration curves were shown in Supplementary Table 7. The cytoplasmic and nuclear levels of CDCA, UDCA, TCDCA, TUDCA, CA, and TCA in HEK293T cells and liver tissues were also determined using UPLC-MS/MS.

\section{Real-time PCR analysis}

Total RNA was isolated from mice livers using TRIzol $^{\circledR}$ and reverse transcribed by a TAKARA cDNA synthesis kit (TAKARA). The resulting cDNA was subjected to quantitative PCR analysis using $\mathrm{SYBR}^{\circledR}$ Green and ABI-StepOnePlus Sequence Detection System (Applied Biosystems, CA, USA). Primer sequences are listed in Supplementary Table 8 . The relative mRNA expression was calculated using the $2^{-\Delta \Delta \mathrm{Ct}}$ method. The expression of glyceraldehyde 3-phosphate dehydrogenase mRNA was used as the endogenous reference control.

\section{Western blot analysis}

Total proteins was extracted from liver tissues, resolved by sodium dodecyl sulfate-polyacrylamide gel electrophoresis, and transferred to polyvinylidene fluoride membranes, which were subsequently probed with primary antibodies raised against Bsep, Mrp2, Mrp3, FXR, ICAM-1 (Santa Cruz, CA, USA), CAR (ABCAM,

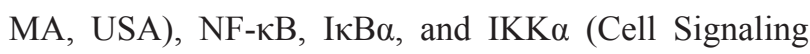
Technology, MA, USA). The membranes were then incubated with the appropriate horseradish peroxidaseconjugated secondary antibodies. The protein bands were detected using the FluorChem E image detection system (ProteinSimple, Santa Clara, CA, USA). Densitometric analysis was performed and the results were expressed as the integrated optical density, relative to $\beta$-actin.

\section{Immunohistochemistry}

Mice livers were fixed in 10\% neutral buffered paraformaldehyde at $4^{\circ} \mathrm{C}$ for $48 \mathrm{~h}$ prior to embedding in paraffin, sectioning, and staining with an anti-Mrp2 antibody (1:500; Santa-Cruz). The sections were finally mounted using DPX Mountant (Sigma, MO, USA) for histological analysis.

\section{Immunofluorescence}

Tissue sections were incubated with a primary antibody (rabbit anti-FXR, 1:200; Santa Cruz) and an Alexa 555-conjugated secondary antibody (1:200; Molecular Probes) to produce an immunofluorescent signal. Sections were counterstained with hematoxylin or 4',6-diamidino-2-phenylindole (eBioscience; 00-4959). Positive staining was quantified manually or using ImagePro Plus 6 Windows Software (Media Cybernetics, USA).

\section{Cell culture}

HEK293T cells were purchased from the Cell Bank of the Shanghai Institutes of Biological Sciences and cultured in normal Dulbecco's modified Eagle's medium containing $10 \%$ fetal bovine serum at $37^{\circ} \mathrm{C}$ in an atmosphere containing $5 \% \mathrm{CO}_{2}$.

\section{Transient transfection and dual luciferase reporter assay}

HEK293T cells were plated onto 48-well plates at a density of $5 \times 10^{5}$ cells $/ \mathrm{mL}$ for $24 \mathrm{~h}$ prior to transfection, and cultured overnight. Cells at 50-70\% confluence were transiently transfected in OPTI-MEM reduced-serum medium (Invitrogen) with a mixture of pFXRE-tk-Luc, pCMV-FXR, and pSG5-retinoid X receptor $\alpha$ expression plasmids (1 $\mu \mathrm{g}$ of each), and the pRL-SV40 Renilla plasmid $(0.1 \mu \mathrm{g}$; Promega) as an internal control for transfection efficiency. All transfections were performed using the Fugene HD transfection reagent (Roche). At $24 \mathrm{~h}$ post-transfection, cells were exposed to the indicated treatments in fresh Dulbecco's modified Eagle's medium containing $10 \%$ fetal bovine serum for an additional $24 \mathrm{~h}$. After treatment, the cells were lysed and luciferase activity was determined using the Dual-Luciferase ${ }^{\circledR}$ Reporter Assay System (Promega, USA), according to the manufacturer's protocol. Luminescence was measured by 
the FB12 luminometer (Berthold, Germany). The firefly luciferase activity was normalized to the Renilla luciferase activity for each well. All experiments were conducted in triplicate and were repeated at least twice.

\section{rNtcp-transfected HEK293T cells and BA uptake}

rNtcp-expressing HEK293T cells were obtained by transient transfection with plasmids, as described previously [55]. Luciferase activity was repeatedly determined to compare transfected and non-transfected cells. The uptake of BAs or CBP by rNtcp-HEK293T cells and the intracellular distribution of taurineconjugated BAs were determined. Twenty-four hours after transfection, the cells were incubated in medium at $37^{\circ} \mathrm{C}$ for $10 \mathrm{~min}$ prior to adding the indicated concentrations of BAs or CBP and incubating for $15 \mathrm{~min}$. The cytoplasmic and nuclear fractions of these cells, and those of the liver tissue obtained from the in vivo study, were separated using the NE-PER nuclear and cytoplasmic extraction reagent (Thermo Scientific, USA). The BAs were then determined using UPLC-MS/MS, as described above.

\section{Statistical analysis}

Data are expressed as the mean \pm the standard deviation (SD). The statistical differences between the study groups were determined by one-way ANOVA analysis. For all comparisons, $\mathrm{p}<0.05$ was considered to represent a statistically significant difference.

\section{CONFLICTS OF INTEREST}

The authors have declared that no conflicts of interest exists.

\section{GRANT SUPPORT}

This work is supported by grants from the National Natural Science Foundation of China (No. 81503343), China; National S\&T Major Project (2014ZX09301306007), China.

\section{REFERENCES}

1. Meng Q, Chen XL, Wang CY, Liu Q, Sun HJ, Sun PY, Huo XK, Liu ZH, Yao JH, Liu KX. Alisol B 23-acetate protects against ANIT-induced hepatotoxity and cholestasis, due to FXR-mediated regulation of transporters and enzymes involved in bile acid homeostasis. Toxicol Appl Pharmacol. 2015; 283: 178-186.

2. Boyer JL. New perspectives for the treatment of cholestasis: lessons from basic science applied clinically. J Hepatol. 2007; 46: 365-371.

3. Chen P, Li J, Fan X, Zeng H, Deng R, Li D, Huang M, $\mathrm{Bi}$ H. Oleanolic acid attenuates obstructive cholestasis in bile duct-ligated mice, possibly via activation of NRF2MRPs and FXR antagonism. Eur J Pharmacol. 2015; 765: 131-139.

4. Beuers U, Trauner M, Jansen P, Poupon R. New paradigms in the treatment of hepatic cholestasis: from UDCA to FXR, PXR and beyond. J Hepatol. 2015; 62: S25-S37.

5. Cuperus FJ, Claudel T, Gautherot J, Halilbasic E, Trauner $\mathrm{M}$. The role of canalicular ABC transporters in cholestasis. Drug Metab Dispos. 2014; 42: 546-560.

6. Li T, Apte U. Bile acid metabolism and signaling in cholestasis, inflammation, and cancer. Adv Pharmacol. 2015; 74: 263-302.

7. Liu J, Lu YF, Zhang Y, Wu KC, Fan F, Klaassen CD. Oleanolic acid alters bile acid metabolism and produces cholestatic liver injury in mice. Toxicol Appl Pharmacol. 2013; 272: 816-824.

8. Chen J, Zhao KN, Chen C. The role of CYP3A4 in the biotransformation of bile acids and therapeutic implication for cholestasis. Ann Transl Med. 2014; 2: 7.

9. de Lima Toccafondo Vieira M, Tagliati CA. Hepatobiliary transporters in drug-induced cholestasis: a perspective on the current identifying tools. Expert Opin Drug Metab Toxicol. 2014; 10: 581-597.

10. Pan X, Jeong H. Estrogen-induced cholestasis leads to repressed CYP2D6 expression in CYP2D6-humanized mice. Mol Pharmacol. 2015; 88: 106-112.

11. Dixon PH, Williamson C. The pathophysiology of intrahepatic cholestasis of pregnancy. Clin Res Hepatol Gastroenterol. 2016; 40: 141-153.

12. Kullak-Ublick GA, Stieger B, Meier PJ. Enterohepatic bile salt transporters in normal physiology and liver disease. Gastroenterology. 2004; 126: 322-342.

13. Delaunay JL, Durand-Schneider AM, Dossier C, Falguières T, Gautherot J, Anne DS, Aït-Slimane T, Housset C, Jacquemin E, Maurice M. A functional classification of $\mathrm{ABCB} 4$ variations causing progressive familial intrahepatic cholestasis type 3. Hepatology. 2016; 63: 1620-1631.

14. Reinehr R, Becker S, Keitel V, Eberle A, Grether-Beck $\mathrm{S}$, Häussinger D. Bile salt-induced apoptosis involves NADPH oxidase isoform activation. Gastroenterology. 2005; 129: 2009-2031.

15. Becker S, Reinehr R, Graf D, vom Dahl S, Häussinger D. Hydrophobic bile salts induce hepatocyte shrinkage via NADPH oxidase activation. Cell Physiol Biochem. 2007; 19: 89-98.

16. Fiorucci S, Zampella A, Distrutti E. Development of FXR, PXR and CAR agonists and antagonists for treatment of liver disorders. Curr Top Med Chem. 2012; 12: 605-624.

17. Baghdasaryan A, Chiba P, Trauner M. Clinical application of transcriptional activators of bile salt transporters. Mol Aspects Med. 2014; 37: 57-76.

18. Rizzo G, Renga B, Mencarelli A, Pellicciari R, Fiorucci $\mathrm{S}$. Role of FXR in regulating bile acid homeostasis and 
relevance for human diseases. Curr Drug Targets Immune Endocr Metabol Disord. 2005; 5: 289-303.

19. Chiang JY. Bile acid metabolism and signaling. Compr Physiol. 2013; 3: 1191-1212.

20. Hollman DA, Milona A, van Erpecum KJ, van Mil SW. Anti-inflammatory and metabolic actions of FXR: insights into molecular mechanisms. Biochim Biophys Acta. 2012; 1821: 1443-1452.

21. Balasubramaniyan N, Ananthanarayanan M, Suchy FJ. Nuclear factor-kappaB regulates the expression of multiple genes encoding liver transport proteins. Am J Physiol Gastrointest Liver Physiol. 2016; 310: G618-G628.

22. Han JM, Kim HG, Choi MK, Lee JS, Lee JS, Wang JH, Park HJ, Son SW, Hwang SY, Son CG. Artemisia capillaris extract protects against bile duct ligation-induced liver fibrosis in rats. Exp Toxicol Pathol. 2013; 65: 837-844.

23. Liu D, Wu T, Zhang CL, Xu YJ, Chang MJ, Li XP, Cai HJ. Beneficial effect of Calculus Bovis Sativus on $17 \alpha$-ethynylestradiol-induced cholestasis in the rat. Life Sci. 2014; 113: 22-30.

24. Ou QQ, Qian XH, Li DY, Zhang YX, Pei XN, Chen JW, Yu L. Yinzhihuang attenuates ANIT-induced intrahepatic cholestasis in rats through upregulation of Mrp2 and Bsep expressions. Pediatr Res. 2016; 79: 589-595.

25. Su J. Tang Materia Medica. Anhui Science \& Technology Publishing House, Anhui, China, 2005: 212.

26. Tao HJ, Yi M, Lu B. People's Medical Publishing House (PMPH), Beijing, China, 1986: 79.

27. Nanjing university of tradional Chinese medicine. Zhong Yao Da Ci Dian. Shanghai Scientific \& Technical Publishers, Shanghai, China, 2006: 1680.

28. Dawson PA, Karpen SJ. Intestinal transport and metabolism of bile acids. J Lipid Res. 2015; 56: 1085-1099.

29. Wang $M$, Zhang X, Xiong X, Yang Z, Sun Y, Yang Z, Hoffman RM, Liu Y. Efficacy of the Chinese traditional medicinal herb Celastrus orbiculatus Thunb on human hepatocellular carcinoma in an orthothopic fluorescent nude mouse model. Anticancer Res. 2012; 32: 1213-1220.

30. Zhang L, Wu C, Zhang Y, Liu F, Zhao M, Bouvet M, Hoffman RM. Efficacy comparison of traditional Chinese medicine LQ versus gemcitabine in a mouse model of pancreatic cancer. J Cell Biochem. 2013; 114: 2131-2137.

31. Zhang $\mathrm{L}, \mathrm{Wu} \mathrm{C}$, Zhang $\mathrm{Y}$, Liu F, Wang X, Zhao M, Hoffman RM. Comparison of efficacy and toxicity of traditional Chinese medicine (TCM) herbal mixture LQ and conventional chemotherapy on lung cancer metastasis and survival in mouse models. PLoS One. 2014; 9: e109814.

32. Yin G, Tang D, Dai J, Liu M, Wu M, Sun Y, Yang Z, Hoffman RM, Li L, Zhang S. Combination efficacy of Astragalus membranaceus and Curcuma wenyujin at different atages of tumor progression in an imageable orthotopic nude mouse model of metastatic human ovarian cancer expressing red fluorescent protein. Anticancer Res. 2015; 35: 3193-3207.
33. Zhang AH, Sun H, Wang ZG, Sun WJ, Wang P, Wang XJ. Metabolomics: towards understanding traditional Chinese medicine. Planta Med. 2010; 76: 2026-2035.

34. Yuliana ND, Khatib A, Choi YH, Verpoorte R. Metabolomics for bioactivity assessment of natural products. Phytother Res. 2011; 25: 157-169.

35. Dai W, Wei C, Kong H, Jia Z, Han J, Zhang F, Wu Z, Gu Y, Chen S, Gu Q, Lu X, Wu Y, Xu G. Effect of the traditional Chinese medicine tongxinluo on endothelial dysfunction rats studied by using urinary metabonomics based on liquid chromatography-mass spectrometry. J Pharm Biomed Anal. 2011; 56: 86-92.

36. $\mathrm{Hu} \mathrm{C}$, Wei H, Kong H, Bouwman J, Gonzalez-Covarrubias V, van der Heijden R, Reijmers TH, Bao X, Verheij ER, Hankemeier T, Xu G, van der Greef J, Wang M. Linking biological activity with herbal constituents by systems biology-based approaches: effects of Panax ginseng in type 2 diabetic Goto-Kakizaki rats. Mol Biosyst. 2011; 7 : 3094-3103.

37. Dong $\mathrm{H}$, Zhang A, Sun H, Wang H, Lu X, Wang M, $\mathrm{Ni} \mathrm{B}$, Wang $\mathrm{X}$. Ingenuity pathways analysis of urine metabolomics phenotypes toxicity of Chuanwu in Wistar rats by UPLC-Q-TOF-HDMS coupled with pattern recognition methods. Mol Biosyst. 2012; 8: 1206-1221.

38. Allen K, Jaeschke H, Copple BL. Bile acids induce inflammatory genes in hepatocytes: a novel mechanism of inflammation during obstructive cholestasis. Am J Pathol. 2011; 178: 175-186.

39. Gao Y, Feng J, Ma K, Zhou Z, Zhu Y, Xu Q, Wang X. 8,9-Epoxyeicosatrienoic acid inhibits antibody production of B lymphocytes in mice. PLoS One. 2012; 7: e40258.

40. Althurwi HN, Maayah ZH, Elshenawy OH, El-Kadi AO. Early changes in cytochrome P450s and their associated arachidonic acid metabolites play a crucial role in the initiation of cardiac hypertrophy induced by isoproterenol. Drug Metab Dispos. 2015; 43: 1254-1266.

41. Chen W, Yang S, Ping W, Fu X, Xu Q, Wang J. CYP2J2 and EETs protect against lung ischemia/reperfusion injury via anti-inflammatory effects in vivo and in vitro. Cell Physiol Biochem. 2015; 35: 2043-2054.

42. Chiang JY. Bile acids: regulation of synthesis. J Lipid Res. 2009; 50: 1955-1966.

43. Yuan ZQ, Li KW. Role of farnesoid $\mathrm{X}$ receptor in cholestasis. J Dig Dis. 2016; 17: 501-509.

44. Wang YD, Chen WD, Wang M, Yu D, Forman BM, Huang W. Farnesoid X receptor antagonizes nuclear factor kappaB in hepatic inflammatory response. Hepatology. 2008; 48: 1632-1643.

45. Mulder J, Karpen SJ, Tietge UJ, Kuipers F. Nuclear receptors: mediators and modifiers of inflammationinduced cholestasis. Front Biosci (Landmark Ed). 2009; 14: 2599-2630.

46. Huijghebaert SM, Hofmann AF. Influence of the amino acid moiety on deconjugation of bile acid amidates by 
cholylglycine hydrolase or human fecal cultures. J Lipid Res. 1986; 27: 742-752.

47. Ferrandi EE, Bertolesi GM, Polentini F, Negri A, Riva S, Monti D. In search of sustainable chemical processes: cloning, recombinant expression, and functional characterization of the 7alpha- and 7beta-hydroxysteroid dehydrogenases from Clostridium absonum. Appl Microbiol Biotechnol. 2012; 95: 1221-1233.

48. Ji Q, Tan J, Zhu L, Lou D, Wang B. Preparing tauroursodeoxycholic acid (TUDCA) using a doubleenzyme-coupled system. Biochem Eng J. 2016; 105: 1-9.

49. Ridlon JM, Kang DJ, Hylemon PB, Bajaj JS. Bile acids and the gut microbiome. Curr Opin Gastroenterol. 2014; 30: 332-338.

50. Rolo AP, Palmeira CM, Wallace KB. Interactions of combined bile acids on hepatocyte viability cytoprotection or synergism. Toxicol Lett. 2002; 126: 197-203.

51. Adachi T, Kaminaga T, Yasuda H, Kamiya T, Hara H. The involvement of endoplasmic reticulum stress in bile acidinduced hepatocellular injury. J Clin Biochem Nutr. 2014; 54: 129-135.
52. Huang Y, Tian Y, Li G, Li Y, Yin X, Peng C, Xu F, Zhang Z. Discovery of safety biomarkers for realgar in rat urine using UFLC-IT-TOF/MS and 1H NMR based metabolomics. Anal Bioanal Chem. 2013; 405: 4811-4822.

53. Yang L, Xiong A, He Y, Wang Z, Wang C, Wang Z, Li W, Yang L, Hu Z. Bile acids metabonomic study on the $\mathrm{CCl}_{4}$ and $\alpha$-naphthylisothiocyanate-induced animal models: quantitative analysis of 22 bile acids by ultraperformance liquid chromatography- mass spectrometry. Chem Res Toxicol. 2008; 21: 2280-2288.

54. Yang F, Xu Y, Xiong A, He Y, Yang L, Wan YJ, Wang Z. Evaluation of the protective effect of Rhei Radix et Rhizoma against $\alpha$-naphthylisothiocyanate induced liver injury based on metabolic profile of bile acids. J Ethnopharmacol. 2012; 144: 599-604.

55. König J, Klatt S, Dilger K, Fromm MF. Characterization of ursodeoxycholic and norursodeoxycholic acid as substrates of the hepatic uptake transporters OATP1B1, OATP1B3, OATP2B1 and NTCP. Basic Clin Pharmacol Toxicol. 2012; 11: 81-86. 